\title{
ARTICLE \\ Designing of the Wireless Digital Portable Temperature and Humidity Monitoring Device and Analyzing Data at Different Part of Kathmandu Valley
}

\author{
Sabina Bogati Mahesh Sharma Rajesh Shrestha* \\ Tri-Chandra Multiple College, TU, Ghantaghar, Nepal
}

\section{ARTICLE INFO}

Article history

Received: 24 April 2021

Accepted: 7 June 2021

Published Online: 9 June 2021

Keywords:

Arduino UNO

HC-05 Bluetooth module

$16 \times 2$ LCD

DHT-11 sensor and wireless

\begin{abstract}
The atmosphere of planet plays a great role in numerous weather phenomena which affects our life directly. To understand these phenomena, it requires knowledge about the relation between temperature and humidity. The effects of temperature on humidity influence the potential for precipitation. It also directly influences the human health and well-being. Relative humidity and dew point are the two parameters that are used by the meteorologists for understanding the interaction between temperature and humidity. Therefore there is a necessary of a smart monitoring system which is fully automated, accurate and capable enough to monitor all the parameters with accuracy. Besides, it should be portable and less expensive. For this purpose, the digital portable wireless temperature and humidity monitoring device is designed. This project consists of HC-05 Bluetooth module, DHT11, Arduino UNO, 16 X 2 LCD, and smartphone. The data are recorded at different part of Kathmandu Valley with this device wirelessly by using smartphone and analyze it with the help of Origin software.
\end{abstract}

\section{Introduction}

Nowadays smartphones are widely used in our daily life having larger storage capacity, more communication methods, richer entertainment functions, etc. Bluetooth was discovered by telecom vendor Ericsson in 1994, which is used to exchange data, add new features to smartphones ${ }^{[1]}$. A Bluetooth is a wireless device which is capable to communicate with up to seven Bluetooth modules at the same time through one link. It has its limited area nearly $10 \mathrm{~m}$ to other Bluetooth devices. With the modernization of technology, the smart living introduces to the people's life. The smartphones give platform to use the Bluetooth base application.It has gradually turned into all-purpose portable device and provided us data for our daily used ${ }^{[2]}$.

Nowadays smartphones consist of people-centric sensing technology such as "CoSoBlue" framework which is used for Bluetooth based social sensing ${ }^{[3]}$. Lattepanda and ThingSpeak are the two tools used for data cloud in remote monitoring system of temperature and humidity. First, the hardware reads data from the sensor and second,

*Corresponding Author:

Rajesh Shrestha,

Tri-Chandra Multiple College, TU, Ghantaghar, Nepal;

Email: rajeshshrestha402@gmail.com 
the data sending to ThingSpeak which is the internet base system for monitoring sensor data. From this system, the temperature and humidity monitored in real time ${ }^{[4]}$. DHT 11 is widely used for measuring the temperature and humidity of surrounding which has a temperature and humidity accuracy of $\pm 1^{\circ}$ and able to measure the temperature range from $0^{\circ}$ to $60^{\circ}$ and humidity ranges from $0^{\circ}$ to $95^{0[5]}$.

The ESP 8266 based Wi-Fi module Node MCU along with DHT 11 is also used for monitoring the temperature and humidity of the surrounding for calculating the Dew point and access the data through SMS, an Email and Tweet post too ${ }^{[6]}$. The technology plays a great role in changing the human life and Internet of Things (IOT) makes it possible. By using Message Queuing Telemetry Transport (MQTT) protocol the remote sensing device working properly with accuracy ${ }^{[7]}$.

This paper deals with the design of digital portable low cost sensing device for monitoring the sensor data of temperature and humidity wirelessly with smartphone using Bluetooth technology. The experimental setup includes temperature \& humidity sensor (DHT-11), 16X2 LCD, HC-05 Bluetooth module and Arduino. The programming codes are developed in Arduino IDE Software and upload it in Arduino Uno board.

\section{Literature Review}

Temperature, humidity, soil moisture and temperature, carbon dioxide level etc are the main component for the growth of plants in greenhouse. For the healthy growth of plant it needs minimum level of these components whereas maximum for the flowers and the fruits. By measuring the temperature and humidity only does not give the accurate observation which cause the optimal result. By increasing the number of sensor stations in the green house, the accuracy in measurement of change in environmental components increases. It also cause the increased in the maintenance cost of the sensor stations. The wireless greenhouse climate monitoring system also design to measures the temperature and humidity which consists of three units. First one is Sensor Station (SS). Second one is Coordinator Station (CS) and the third one is Central Control Station (CCS). ZigBee modules are used as a wireless communication between the Sensor Station and Coordinator station. Similarly, RF modem is used for the communication between the Coordinator Station and Central Control Station. The device is cost effective in size, price, and low power consumption ${ }^{[8]}$.

The low cost portable sensor device also design for real time measurement of data from the dust particles in the open environment. It also design by low cost hardware and reliable in the calibration of temperature and humidity of the environmental parameters. It is also used for calculating the air dust density and most useful for indoor and outdoor applications. The Bluetooth module and the AES data encryption technology also include in this device for real time data transfer and monitoring system. Thus, such device measures data with higher accuracy at lower-cost than that of commercially available air quality sensor device $^{[9]}$.

Another work is done in the related topic with a fully wireless sensory system where the sensor part does not contain any chip. By using the reader antenna, the changes in the parameter of data observed by the reader through inductive coupling device with the help of varying its frequency response. The sensor part is made by LC circuit by using substrate. The electrical permittivity change with the moisture content in it ${ }^{[10]}$.

In most of the agricultural field the wireless sensor network plays a great role for monitoring and controlling the greenhouse parameter. There are lots of advance technology introduced in the agricultural field and its development in the last decades. As the rain water distribution is uneven which cause problem to the farmers to monitor and control it to equal distribution. Due to the lack of knowledge to ideal irrigation method, soil structure and choice of the variety of crops for all weather condition the farmers faced lots of problem in agricultural field. The ultimate solution of it is the green house technology. So, the wireless sensor technology and miniaturized sensor devices helps to monitor the environmental parameters in real time and controlling the parameters of green house for precision agriculture application. Programmable System on Chip Technology is used as wireless sensor networks for monitoring and controlling the greenhouse environmental parameters ${ }^{[11]}$.

\section{Methodology}

The Block diagram of wireless real time temperature and humidity monitoring system using DHT-11 sensor is shown in Figure 1. According to the programming used in Arduino Uno, the sensor data convert from analog to digital form and display it to the Liquid Crystal Display (LCD), and the same data can be viewed on the mobile wirelessly using the hc-05 Bluetooth module. Here, The Arduino Uno microcontroller is used for controlling all the systems. 


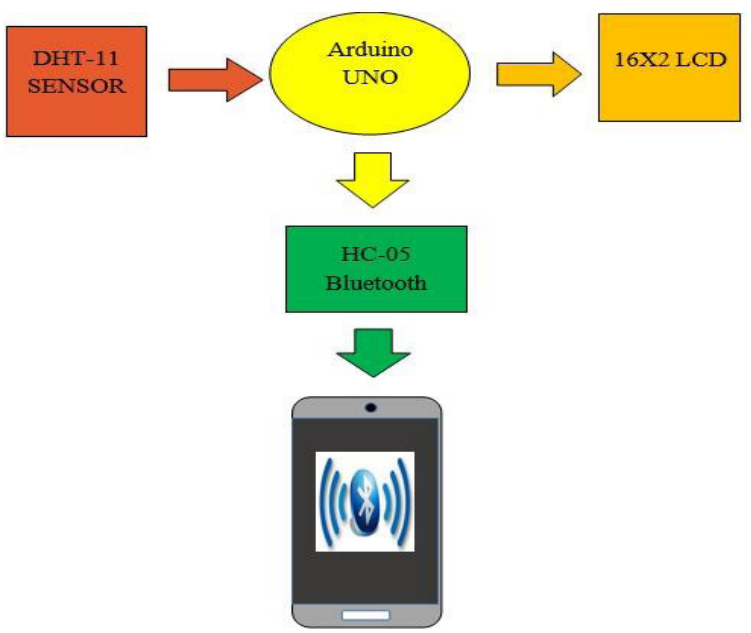

Figure 1. Block Diagram of wireless real time Temperature and Humidity monitoring system

\subsection{Hardware Required}

(1)5 Volt power supply

(2)Arduino UNO (microcontroller)

(3)Bluetooth module

(4)Smart Phone

(5)Battery Connecter

(6) $16 \mathrm{X} 2 \mathrm{LCD}$

(7)DHT-11

(8) $10 \mathrm{k}, 4.7 \mathrm{k}$ and $1 \mathrm{k}$ resistor

\section{A) Arduino UNO}

Arduino is more popular in the field of electronic and scientific research because it is a new open-source hardware and software system. It contains on board power supply, USB port to communicate with computers, associated with an ATMEL microcontroller chip. It is simple to use and has on board debugger. It can support various types of sensor a module readily available to be interfaced with it. It consumes very less power and delivers greater accurate result. It is inexpensive, open-source and extensible, cross-platform and have clear IDE which increases its use in advancing technology.

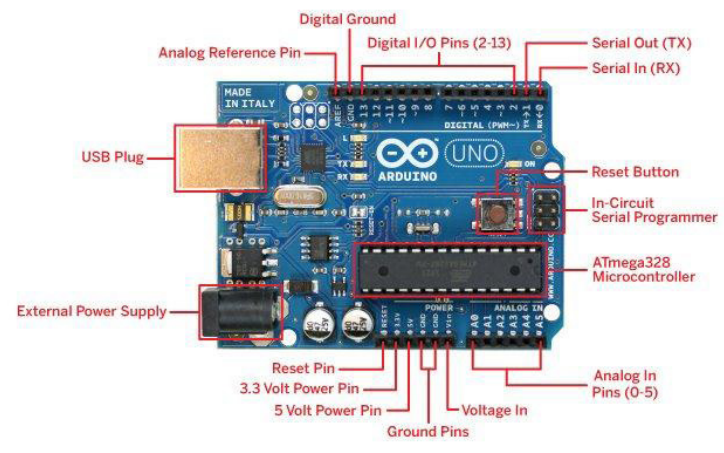

Figure 2. Arduino UNO

\section{B) DHT-11 Sensor}

The DHT-11 (Digital Humidity and Temperature) sensor module sensing the temperature and humidity of the surrounding and gives calibrated digital output signal. The sensor has temperature and humidity measurement component with 8-bit microcontroller for high performance which offers excellent quality, fast response and anti-interference ability and available in 3-pin single row package and also the major feature of this device is that information for each temperature and humidity is obtainable on one data pin of the device. It has small size, low power operating range $(3 \mathrm{~V}-5 \mathrm{~V})$ and up to- $20 \mathrm{~m}$ signal transmission which making it best choice to use in various application that's why it is the most demanding ones.

\section{C) HC-05 Bluetooth Module}

HC-05 Bluetooth module is a simple to apply Bluetooth serial port protocol module. It is completely qualified Bluetooth V2.0+EDR. It uses $2.45 \mathrm{GHZ}$ frequency band. The transfer rate of data can vary up to $1 \mathrm{mbps}$ and is in a range of $10 \mathrm{~m}$. It can be operated within $4-6 \mathrm{v}$ of power supply. It utilizes CRS blue center 04-external single-chip Bluetooth framework with CMOS innovation and with $\mathrm{AFH}$.

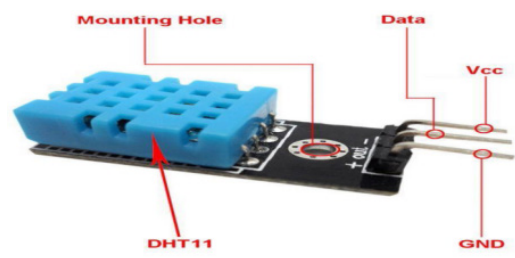

Figure 3. DHT-11 Sensor

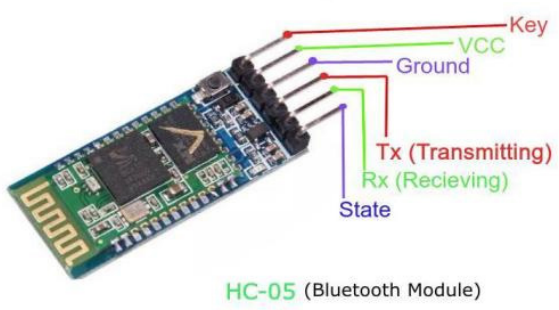

Figure 4. HC-05 Bluetooth Module

\section{D) $16 \times 2$ LCD}

$16 \times 2$ LCD is most widely used in all electronic projects to display the status of the process. It has low cost, easily programmable, display large number of characters and suitable to all micro-controller as well as microprocessor. It has 2-horizontal line contain the space of 16 displaying character. It consists 2 inbuilt resisters i.e., command \& data resister. 


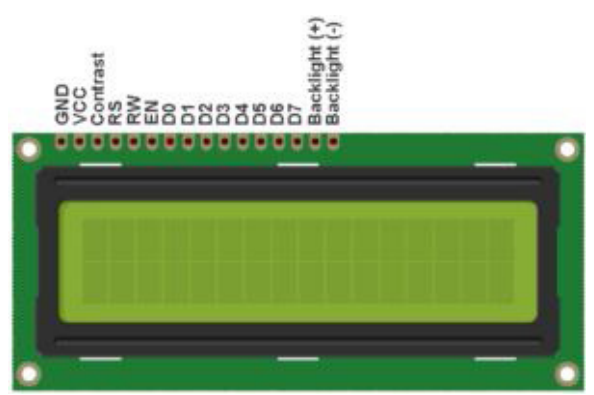

Figure 5. 16 X 2 LCD

\section{E) Resistors}

Resistor is commonly used component in electrical circuit of different application depending upon the current rating voltage and resistance. It is also called the temperature coefficient resistor. It is a 2-terminal device which is used to resist the flow of current. It is derived from Ohm's Law (V=IR). It has different value of resistance, which is described in ohms, which tells how strongly it resists the current. Resistors get in different forms, size and shapes. It consists of 3 colored strips which indicate the value of resistor. Each strip of color of resistor indicates the specific digit. The different colors of digits are as shown in below figures.

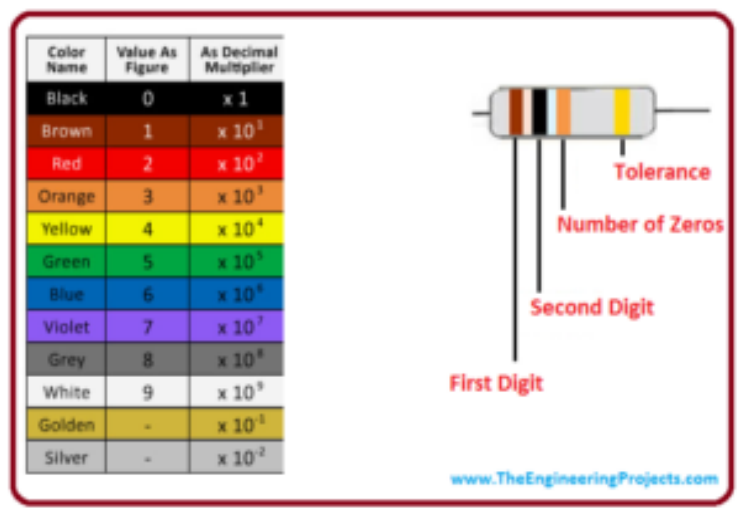

Figure 6. Different colors with their digits of Resistor

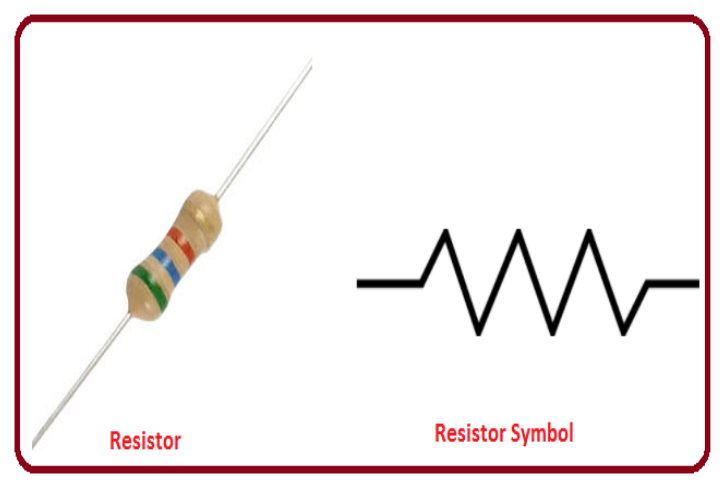

Figure 7. Resistor

\subsection{Software}

To program the Arduino UNO, we used here the Arduino IDE (Integrated Development Environment) which is the free software that enables us to program in the language that the Arduino understands. The IDE enables us to write the computer program in the Arduino UNO.

\subsection{Circuit Diagram and Working}

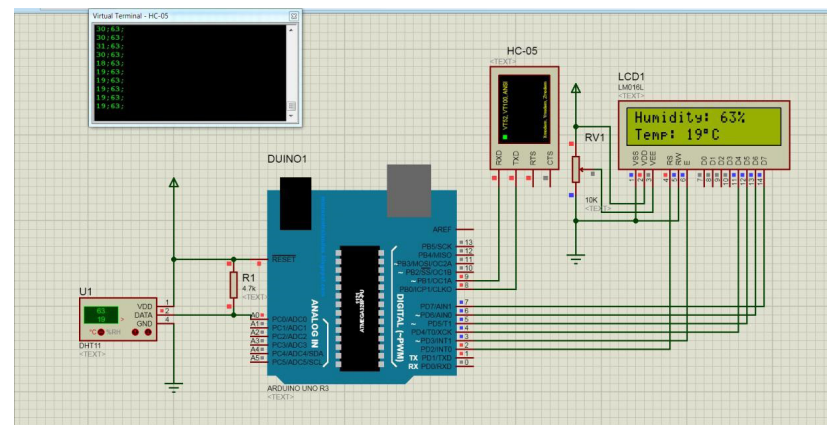

Figure 8. Circuit diagram of the system

The circuit diagram for the temperature and humidity monitoring using hc-05 Bluetooth is shown in the above figure. DHT-11 sensor is used for the sensing the temperature and humidity of our surrounding. DHT-11 sensor's DATA, VCC and GND Pins are connected at A0, 5V and GND of Arduino respectively. The $16 \times 2$ LCD pins $4,6,11,12,13,14$ are connected to digital pins 2, 3, 4, 5, 6, 7 of Arduino respectively and $1 \& 16$ pin of LCD connected to the ground similarly, pin 2 for VCC and pin 3 is connected to the $4.7 \mathrm{k}$ resistor of one point and middle point of resistor is connected to the A0 of Arduino and pin number 15 is connected to the $10 \mathrm{k}$ resistor and another end of resistor is connected to the ground. The Tx and Rx pins of $\mathrm{HC}-05$ Bluetooth module are directly connected to 8 \& 9 pin no of Arduino. The VCC and GND pin of Bluetooth is connected at $5 \mathrm{v}$ and GND of Arduino UNO.

The Arduino UNO converts the analog data of sensor device into digital data and the digital values of temperature and humidity displayed on the $16 \times 2$ LCD as well as in the smartphone at the real time with the help of HC-05 Bluetooth module.

\section{Results}

The final outlook of the wireless digital portable temperature and humidity monitoring system is shown in fig 9 .

\subsection{Result Obtained at Mulpani}

The plotting of temperature and humidity with respect to the time from $7 \mathrm{AM}$ to $3.30 \mathrm{PM}$ is shown in figure below. 


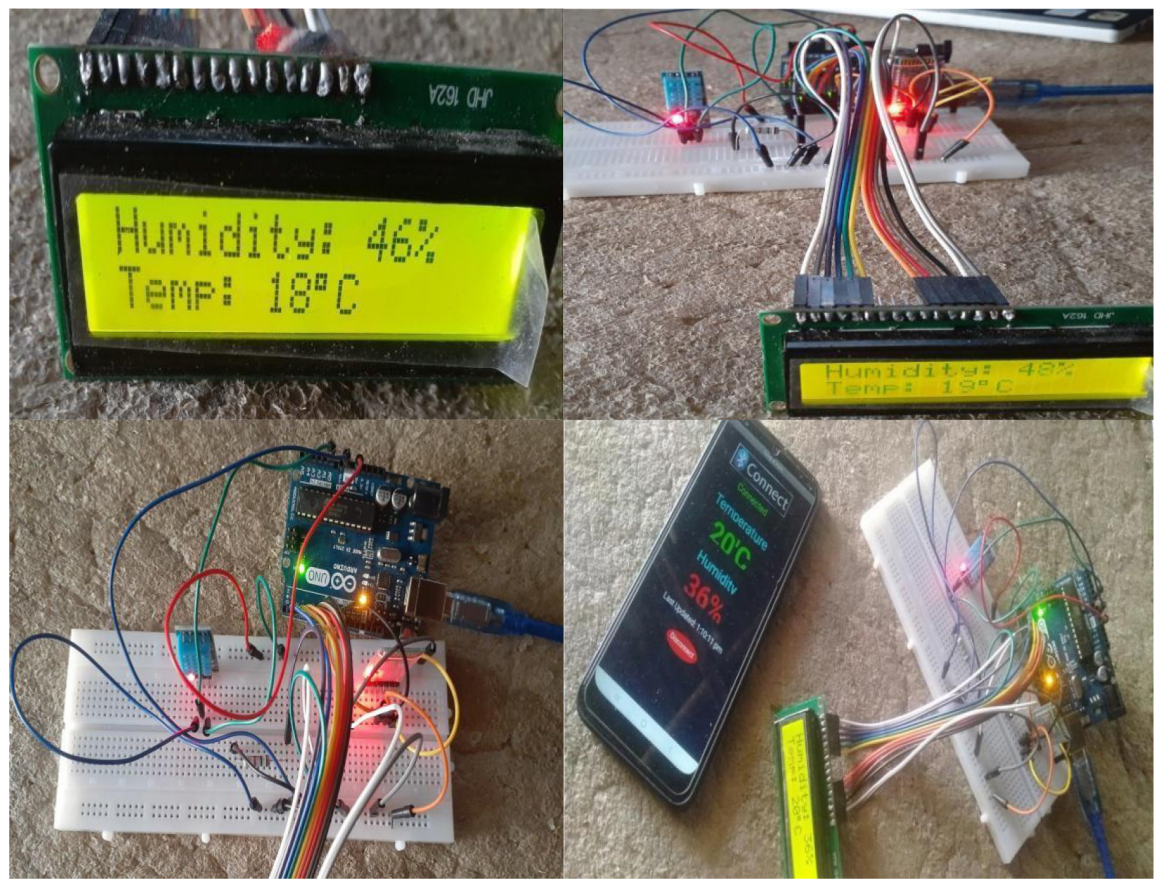

Figure 9. Wireless Temperature \& Humidity Monitoring System
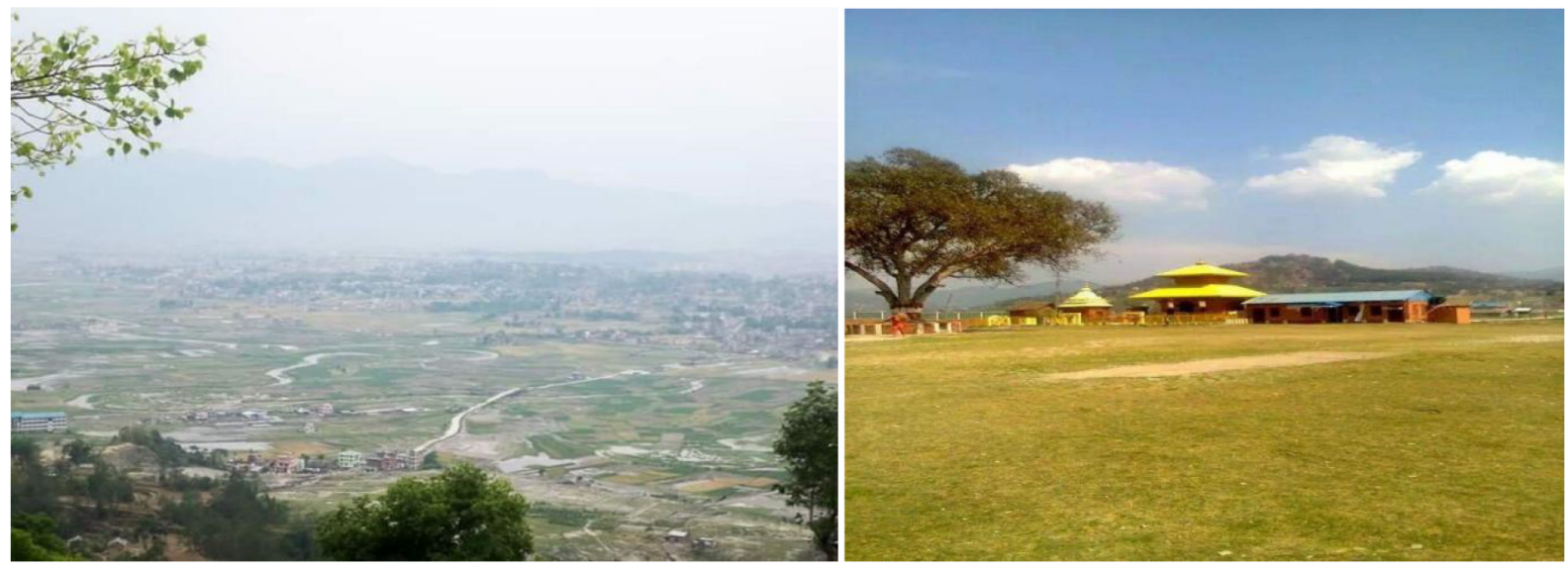

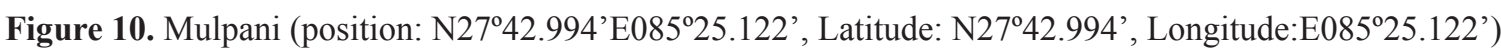

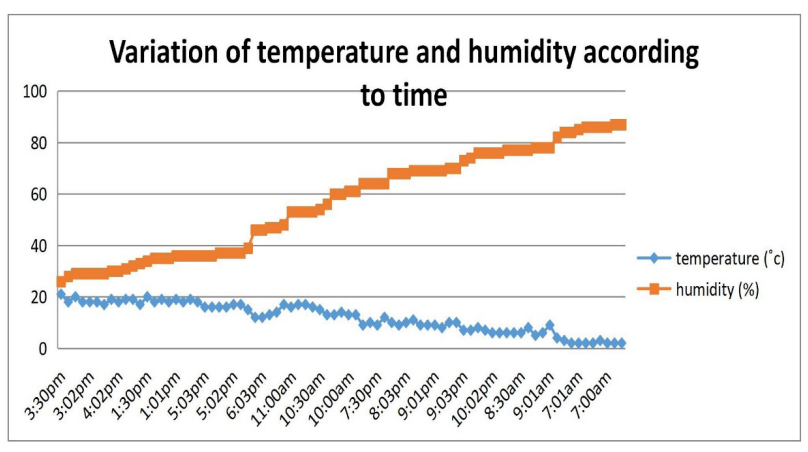

Figure 11. Variation of Temperature and Humidity with respect to Time obtained by using this device at Mulpani Also, the variation of humidity with respect to tempera- ture at Mulpani is shown in fig below.

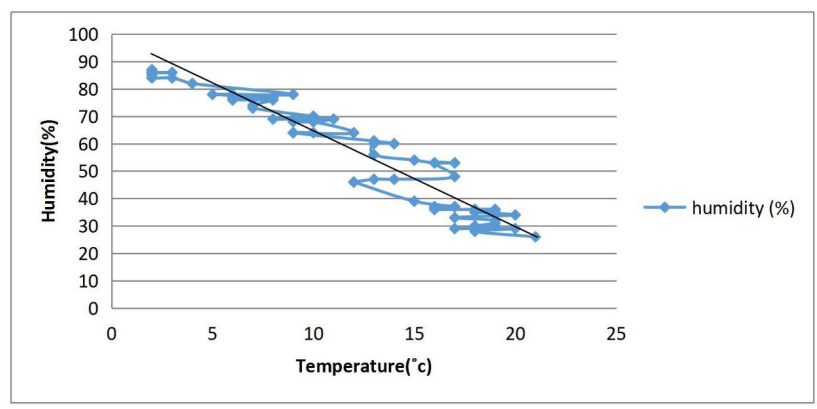

Figure 12. Variation of Humidity and Temperature using this device at Mulpani 
4.2 Result Obtained from Pashupatinath Temple, Chabahil

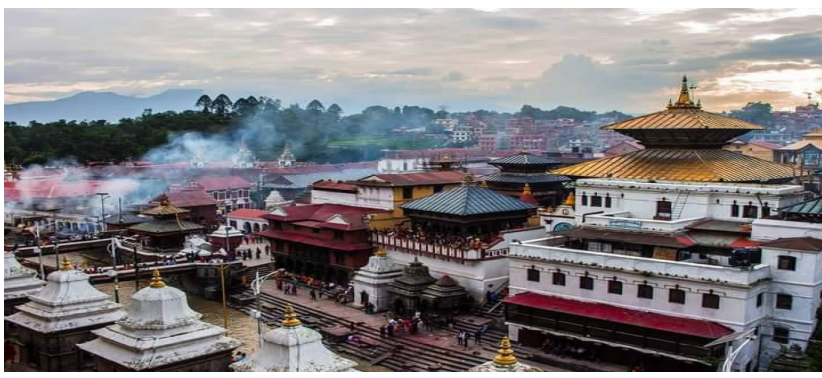

Figure 13. Pashupatinath Temple, Chabahil (position: $\mathrm{N} 27^{\circ} 42.587^{\prime} \mathrm{E} 085^{\circ} 21.110^{\prime}$, Latitude: N27 $42.587^{\prime}$, Longitude: E085'21.110', Altitude: 4190ft)

The variation of temperature and humidity with respect to time from 12:50 PM to 2:50 PM using this device is shown in figure below.

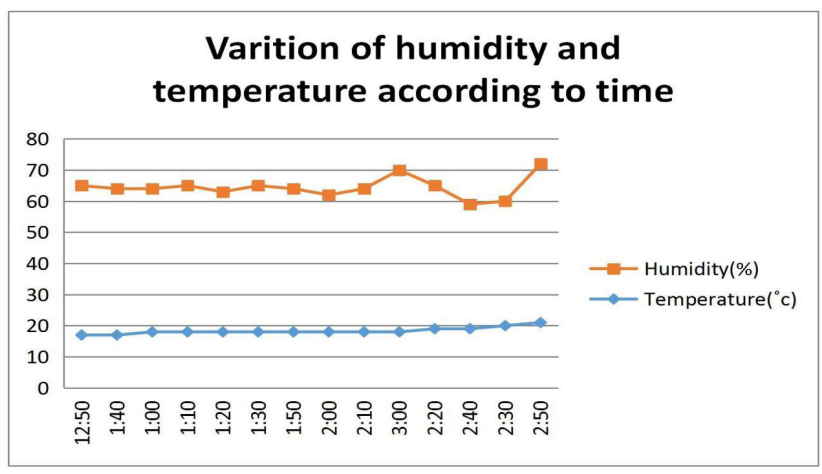

Figure 14. Variation of Temperature and Humidity with respect to Time obtained by using this device at Pashupatinath Temple, Chabahil

Also, the variation of humidity with respect to temperature at this location is shown below.

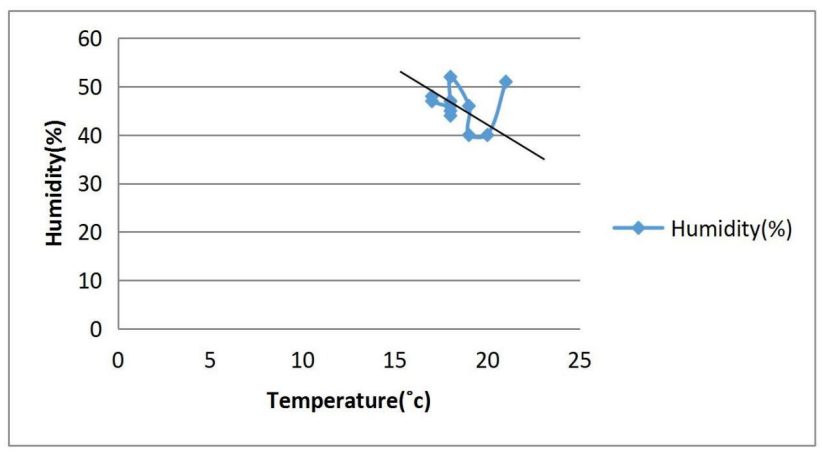

Figure 15. Variation of Humidity and Temperature using this device at Pashupatinath Temple, Chabahil

\subsection{Comparison and Analysis of Data}

The linear and polynomial fitting on the variation of temperature Vs humidity is shown in figure below.

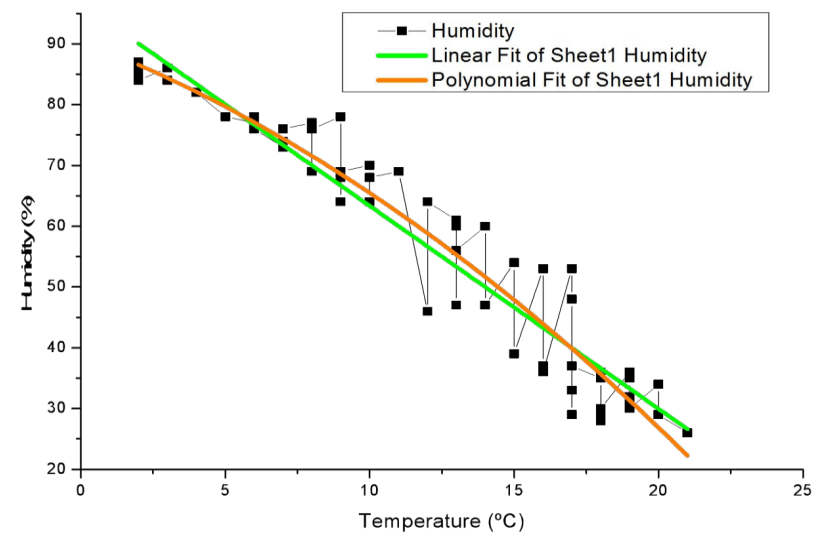

Figure 16. Polynomial and Linear fitting of data using Origin Software.

The standard errors of linear fitting of data is shown in table below.

Table 1. linear fitting of data using Origin Software

\begin{tabular}{|c|c|c|c|c|}
\hline & $\mathrm{A}$ & $\mathrm{B}$ & $\mathrm{C}$ & $\mathrm{D}$ \\
\hline 1 & Equation & $y=a+b^{*} x$ & & \\
\hline 2 & Weight & No Weighting & & \\
\hline 3 & $\begin{array}{l}\text { Residual Sum } \\
\text { of Squares }\end{array}$ & 2643.47574 & & \\
\hline 4 & Pearson's r & -0.95614 & & \\
\hline 5 & Adj. R-Square & 0.91309 & & \\
\hline 6 & & & Value & Standard Error \\
\hline 7 & \multirow{2}{*}{ Humidity } & Intercept & 96.72304 & 1.54228 \\
\hline 8 & & Slope & -3.33875 & 0.11656 \\
\hline
\end{tabular}

The standard errors of polynomial fitting of data is shown in table below.

Table 2. Polynomial fitting of data using Origin Software.

\begin{tabular}{|c|c|c|c|c|}
\hline & $\mathrm{A}$ & $B$ & $\mathrm{C}$ & $\mathrm{D}$ \\
\hline 1 & Eguation & \multicolumn{3}{|c|}{$y=$ Intercept $+B 1^{*} x^{\wedge} 1+B 2^{\star} x^{\wedge} 2$} \\
\hline 2 & Weight & No Weighting & & \\
\hline 3 & $\begin{array}{l}\text { Residual Sum } \\
\text { of Squares }\end{array}$ & 2366.82557 & & \\
\hline 4 & Adj. R-Square & 0.92116 & & \\
\hline 5 & & & Value & Standard Error \\
\hline 6 & & Intercept & 90.46008 & 2.56383 \\
\hline 7 & Humidity & B1 & -1.81916 & 0.52179 \\
\hline 8 & & B2 & -0.06805 & 0.02283 \\
\hline
\end{tabular}

\section{Conclusions}

In this paper, we discussed about the wireless digital portable Temperature \& Humidity Monitoring system using HC-05 Bluetooth module, DHT 11 and Arduino Uno. It works with DHT-11 sensors and measures the real time temperature and humidity of our surroundings. To find the accuracy and validity of data measured by this device, 
we recorded data in two different locations of Kathmandu valley at Pashupatinath Temple, Chabahil and Mulpani, Bhaktapur. The data of temperature and humidity measured by this device has fitted with linear line and polynomial curve using Origin Software. The standard error of intercept in linear fitting in relation between humidity and temperature by DHT-11 sensor obtained as 1.54228 and in polynomial fitting the standard error obtained as 2.56383 respectively. Hence we have seen that our device is reliable in the measurement of temperature and humidity with DHT-11 sensor wirelessly.

This concludes that the present proposed work was successful and it provides a convenient method for the effective monitoring of temperature and humidity in a real time wirelessly. This system has compact to an extent and cost effective when compared to prices of instruments used to measure the environmental factors. From all above the analysis, it is ensured that the nested wired systems can be replaced by the wireless sensor networks to get accurate data as well as to avoid many hazardous issues.

\section{Summary and Recommendation}

The design of wireless digital portable and low cost temperature and humidity monitoring system using $\mathrm{HC}$ 05 Bluetooth Module, DHT 11 and Arduino Uno has been explained in this paper. By using this device, the value of temperature \& humidity can be measured in real time wirelessly through smartphone. The measured value can be monitored in two different ways using LCD display and HC-05 Bluetooth module which display the data on our Smartphone. This device is very useful for researcher, who wants to research in the field of weather forecast, productivity of crops in agriculture field, carbon emission etc. Government can also use this system to alert people if temperature rises to very high or falls down to very low than usual. This device can also be used in TV or radio station to broadcast the temperature and humidity of local area.

$>$ Wi-Fi Connection: This device should be connected with Wi-Fi device and data could also be stored in mobile.

$>$ Increase in sensor: In this device the BMP180, rain sensor, dust sensor, barometric pressure sensor etc. could be added so that it can record other more parameters such as atmospheric pressure, altitude etc.

$>$ Increase in area: This device can be made for a large area too for minimizing the error in recorded data.

$>$ Password protection: The mobile phone can also be password protected for security purpose so that it can be operated only if correct password is entered or necessary modification should be made in the assembly language code. This introduces conditioned access and increases security to a great extent.

\section{Acknowledgment}

I would like to express my special thanks of gratitude to my Physics teacher Co-Supervisor "Mr. Rajesh Shrestha" for their able guidance and support in completing my Project.

I would also like to extend my gratitude to my Supervisor "Mr. Mahesh Sharma" for providing me with all facility that was required.

\section{References}

[1] Ms. Indumathy. T, (2015). An Overview of Bluetooth-Wireless Technology. International Journal of Engineering Research \& Technology, Volume 3 ,Issue 33.

[2] Yan, M., \& Shi, H. (2013). SMART LIVING USING BLUETOOTH- BASED ANDROID SMARTPHONE. International Journal of Wireless \& Mobile Networks, 5, 65-72.

[3] Zhixian, Y., Jun, Y. and Emmanuel, M T. (2013). Smartphone bluetooth based social sensing. In Proceedings of the 2013 ACM conference on Pervasive and ubiquitous computing adjunct publication (UbiComp '13 Adjunct). Association for Computing Machinery, New York, NY, USA, 95-98.

DOI: https://doi.org/10.1145/2494091.2494118.

[4] Nasution,T H ,et al.(2019)"Monitoring temperature and humidity of server room using Lattepanda and ThingSpeak". IOP Publishing Ltd.

[5] Shrestha ,R.(2019). "Study and Control of DHT11 Using Atmega328P Microcontroller.” International Journal of Scientific \& Engineering Research, vol 10,Issue 4,518-521.

[6] R. K. Kodali and S. Mandal, "IoT based weather station," 2016 International Conference on Control, Instrumentation, Communication and Computational Technologies (ICCICCT), 2016, pp. 680-683. DOI: 10.1109/ICCICCT.2016.7988038.

[7] R. K. Kodali and K. S. Mahesh, "A low cost implementation of MQTT using ESP8266," 2016 2nd International Conference on Contemporary Computing and Informatics (IC3I), 2016, pp. 404-408. DOI: 10.1109/IC3I.2016.7917998.

[8] Gupta, G. S., \& Quan, V. M. (2018, March). Multi-sensor integrated system for wireless monitoring of greenhouse environment. In 2018 IEEE sensors applications symposium (SAS) (pp. 1-6). IEEE.

[9] Hojaiji, H., Kalantarian, H., Bui, A. A., King, C. E., \& Sarrafzadeh, M. (2017, March). Temperature and humidity calibration of a low-cost wireless dust sen- 
sor for real-time monitoring. In 2017 IEEE sensors applications symposium (SAS) (pp. 1-6). IEEE.

[10] Salmerón JF, Albrecht A, Kaffah S, Becherer M, Lugli P, Rivadeneyra A. Wireless Chipless System for Humidity Sensing. Sensors. 2018; 18(7):2275. https://doi.org/10.3390/s18072275.
[11] Chaudhary, D. D., Nayse, S. P., \& Waghmare, L. M. (2011). Application of wireless sensor networks for greenhouse parameter control in precision agriculture. International Journal of Wireless \& Mobile Networks (IJWMN), 3(1), 140-149. 